\title{
ПРОИЗВЕДЕНИЕ ИСКУССТВА В ЭПИЦЕНТРЕ ХУДОЖЕСТВЕННОЙ КУЛЬТУРЫ
}

Аннотация. В статье рассматриваются вопросы, связанные с особенностями понятий «культура», «художественная культура», "произведение искусства». Культура определяется как человеческая деятельность по культивированию идеалов; идеалообразование - как процесс сохранения и изменения почитаемых за идеалы образиов воспроизводства общественной жизни и уникальной культурь индивидуального человека. Утверждается, что художественная культура - это подсистема культуры, способная порождать равновесные идеалы. Выделяются и анализируются модели, согласно которым бормируются базовые идеалы культуры. Статья раскрывает сущностный характер произведения искусства как центрального звена художественной культуры, определяет понятия "произведение изобразительного искусства", "художественный образ» в контексте исследования актуальных проблем художественного творчества. Произведение изобразительного искусства исследуется как искусственный и искусно произведенный идеал, искус которого направлен на идеальное (репрезентативное) отночение конечного с конечным и конечного с бесконечным. Рассмотрен творческий процесс диалога художника с художественным материалом, взаимодействие произведения изобразительного искусства со зрителем, сформулирован операиионный подход к взаимодействию зрителя с произведением изобразительного искусства.

Ключевые слова: культура, художественная культура, произведение искусства, художественный образ, художник, художественный материал, идеал, зритель, искусность, модель.

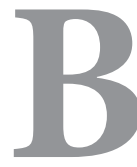

современной науке существует множество концепций культуры, каждая из которых по-своему определяет понятие «культура» (от лат. cultura возделывание, воспитание, образование, развитие, почитание). Одним из наиболее точных определений является синтетическое определение: «культура есть идеалообразующая сторона человеческой жизни и деятельности», подробно изученное и проанализированное Д. В. Пивоваровым ${ }^{1}$.

«Идеал» (фр. ideal) - это образец, нечто совершенное, высшая цель стремления человека и человечества. «Идеал» есть концентрированно явленная сущность, окно в скрытое от человека бытие. «Идеал» это посредник (репрезентант, мост) между человеком и вещью, между людьми, между сознанием и самосознанием индивида, между человеком и космосом.

Синтетическая теория идеального указывает, что образование идеала предполагает соблюдение трех основных условий: наличие чувственного объ-

${ }^{1}$ Пивоваров Д.В. Философия религии. М: Академический проект; Екатеринбург: Деловая книга, 2006. С. 239-261. екта, признаваемого субъектом в качестве эталона; осуществление субъектом интериоризации схемы действия с эталоном; экстраполяция эмпирического знания о свойствах эталона на сверхчувственную реальность.

Таким образом, идеал в снятом виде содержит все качества, в отдельности упоминаемые при традиционном анализе культуры. То, что культивирует культура, это идеалы. Идеалы составляют фундамент культуры. Прочность и долговечность культуры зависит от способности фундаментальных идеалов реализовывать свою «поддерживающую» миссию.

В качестве идеалов могут выступать и научные эталоны, и промышленные образцы, и художественные произведения. Как отличительный признак всякой культуры, идеалообразование есть процесс сохранения и изменения почитаемых за идеалы образцов воспроизводства специфической общественной жизни во всех ее измерениях, а также процесс мучительного расставания с идеалами, перестающими животворно влиять на прирост культуры. Идеалы производятся не только глобальными обществами и цивилизациями, но также отдельными народами, 


\section{Философия и культура 11(71) • 2013}

социальными группами и индивидами. Поэтому правомерно говорить не только о культуре общества или народа, но и об уникальной культуре индивидуально человека ${ }^{1}$.

Носитель культуры соотносится с любым объектом (живым или косным, естественным или искусственным) не непосредственно, а только посредством того или иного «идеала». Отношение носителя культуры с любой сферой бытия позволительно назвать идеальным, поскольку оно случается благодаря идеалу, выступающему в качестве репрезентанта, посредника, медиатора.

Существует несколько моделей, отвечающих на вопрос о том, кто формирует базовые идеалы культуры: «элитарная модель», «модель собора» и «модель индивидуальной эволюции». Согласно «элитарной модели», тот или иной базовый идеал культуры формирует выдающаяся личность, гений в определенной области жизни и знания. Элитарный деятель открывает или изобретает новый идеал, тогда как остальные люди постепенно признают нововведение и начинают культивировать это новшество. Согласно «соборной модели», базовый идеал культуры формируется путем взаимного соглашения или коллективного договора. В этом случае идеал получает статус закона, учреждение которого определяет правила и нормы поведения всех людей данного социума. Возделывание принятого идеала постепенно переходит в традицию.

Согласно «модели индивидуальной эволюции», каждый индивид способен путем постепенной эволюции стать развитым и независимым в вопросах производства и выбора культурных идеалов. Каждый человек способен дорасти до уровня творца собственных идеалов.

«Идеал» есть равновесие внешнего и внутреннего. Внешне (чувственно) «идеал» представлен как «идол», внутренне (сверхчувственно) содержание «идеала» предстает как «идея». «Идеал» есть «идол», являющий «идею» ${ }^{2}$. Таким образом, можно утверждать, что культура есть человеческая деятельность по культивированию, возделыванию, взращиванию идеалов, призванных способствовать процессу уютного, комфортного существования каждого человека с собой, другими людьми, предметами первой и второй природы, мирозданием в целом.

Преобладание в идеалах внешнего (чувственного) или внутреннего (сверхчувственного) «идола»

\footnotetext{
${ }^{1}$ Пивоваров Д.В. Проблема синтеза основных дефиниций культуры // Вестник Российского философского общества. 2009. № 1. C. 157-161.

${ }^{2}$ Там же.
}

или «идеи», дает возможность подразделять культуру на ряд сфер: религиозную, научную, техническую, политическую, экономическую, физическую, правовую, художественную.

В зависимости от масштаба сферы бытия, все культурные идеалы могут быть подразделены на идеалы-репрезентанты «абсолютоцентрического», «космоцентрического», «социоцентрического» либо «эгоцентрического» качества.

Правовая и экономическая культура «озабочены» культивированием идеалов, имеющих социоцентрическое качество. Религиозная культура ответственна за формирование идеалов, имеющих космоцентрическое качество. Физическая культура преимущественно ориентирована на формирование идеалов, обладающих эгоцентрическим качеством.

Подсистема культуры, способная порождать относительно равновесные идеалы, близкие эталонному идеалу гармонии, это художественная культура. Чувственные репрезентанты художественной культуры - уникальные вещи, которые при всей значимости и принципиальной важности своей материальной составляющей, обнаруживают равное присутствие и нематериальной стороны. Понятие «чувственно-явленная сущность», которым определяется идеал, непротиворечиво воплощается в идеалах художественной культуры.

Художественная культура - уникальная сфера культуры. В. И. Даль утверждает, что «изящные художества стремятся к созданию первообраза красоты, союза добра и истины, которых отраженье мы видим в вещественной природе», а также определяет «художественное произведенье» как искусное, мастерское, изящное ${ }^{3}$.

С одной стороны, идеалы художественной культуры интегрируют в себе «идол» и «идею», телесную оболочку и сверхчувственное значение. Идеалы художественной культуры невозможно отнести либо к преимущественно «материальным», либо преимущественно «духовным» феноменам.

С другой стороны, художественная культура есть сфера по культивированию идеалов, способствующих репрезентативному совокуплению как конечного с конечным, так и конечного с бесконечным. Это значит, что идеалы художественной культуры интегрируют в себе «эго», «социо», «космо» и «абсолютоцентрические» аспекты. Они могут служить репрезентантами отношения человека с самим собой, другими людьми, Богом, а в пределе - со всей Полнотой бытия (Абсолютом).

3 Даль В.И. Толковый словарь живого великорусского языка: В 4-х т. М., 1980. Т. 4. С. 569. 


\section{Философия и искусство}

«Художественность» это качественная характеристика произведений изобразительного искусства, способных выступить репрезентантом идеального отношения несовершенной конечности человека с бесконечным Совершенством в его эго-, социо-, космо- и абсолютоцентрической представленности. Строго говоря, только тот «образ» может быть именован «художественным», который обладает потенцией религиозного возрождения (воссоздания, воссоединения) репрезентативного взаимодействия твари с Творцом. В роли «Творца» способна выступить эталонная Личность, эталонный Социум или Божество, однако лишь Абсолют есть подлинно бесконечное Совершенство, явленное в истине Творца.

Поскольку в словосочетании «художественная культура» слово «художественный» означает особое мастерство культурных идеалов, их неповторимые «искусственность», «искусность» и «искус», постольку понятие «художественная культура» есть аналог понятию «искусство».

Искусство - это сфера человеческой деятельности, в границах которой осуществляется мастерское производство и сохранение искусственных, искусных и искушающих идеалов.

Сфера искусства многообразна. Это области искусства кино и театра, музыки и литературы, хореографии и видео.

В свою очередь, область изобразительного искусства - это целый мир, в котором позволительно выделить несколько зон.

Во-первых, область изобразительного искусства включает в себя сеть социальных институтов художественного образования, призванная с малолетства весьма продолжительное время (художественная школа, художественное училище, художественный институт и т.д.) тщательно готовить избранниковтворцов, всю жизнь нацеленных исключительно на производство художественно значимых продуктов.

Во-вторых, мир изобразительного искусства немыслим без институтов, занимающих демонстрацией, изучением и сохранением творческих изделий (музеи, галереи, выставочные залы, библиотеки, научно-исследовательские отделы и лаборатории, реставрационные мастерские и пр.).

В-третьих, проблема купли-продажи творческих продуктов, необходимость определения их подлинности или поддельности, художественной ценности и меновой стоимости привела к возникновению особой категории уникальных экспертов изобразительного искусства - искусствоведов-знатоков, критиков, кураторов, арт-менеджеров и т.п.
В-четвертых, в границах области изобразительного искусства можно обнаружить целый архипелаг, связанный с потреблением творческих продуктов это совокупность печатных изданий по искусству: книги, художественные каталоги, журналы, видеофильмы, Интернет-сайты, Интернет-порталы и др.

В эпицентре области под названием «изобразительное искусство» находится концептуальный стержень, имя которому - произведение изобразительного искусства.

Bсе, что разворачивается в многомерный и многоликий мир искусства, в сжатой до предела форме содержится в этом концентрате, и нигде больше. Только произведение изобразительного искусства в снятом виде фиксирует и уровень технической подготовки художника, и традицию, в которой он воспитывался, и его историческое время, и творческий метод, и художественный стиль, в котором оно исполнено. Именно в произведении изобразительного искусства сосредоточены и особенности его производства, и своеобразие его хранения, и специфика его потребления.

«Изобразительное искусство» есть сфера человеческой деятельности, ответственная за производство и сохранение архитектурных, скульптурных, живописных, графических и декоративных произведений в качестве искусственных, искусных и искушающих идеалов.

«Произведение изобразительного искусства» есть искусственный и искусно произведенный идеал, искус которого направлен на идеальное (репрезентативное) отношение конечного с конечным и конечного с бесконечным.

Произведение искусства - это нечто произведенное из небытия в существование, нечто сотворенное, то есть обретшее статус габаритного предмета в качестве наличного бытия мира «второй» природы. Это часть огромного числа вещей, созданных руками человека-творца, заменившего собой Творца вселенной.

Второприродное произведение искусства в его отношении к первоприродным произведениям негативно определяется как вещь «неестественная», а позитивно предстает как вещь «искусственная».

Произведение искусства - это не обычный элемент сотворенной человеком природы, а та сравнительно небольшая её часть, которая хитро, умело, с расчетом, мастерски произведена людьми. Произведение искусства - это «искусный» продукт деяний образцовых человеческих рук и ума. Искусен Абсолют-Творец - создатель «естественных» произведений, и искусен художник-творец - создатель 


\section{Философия и культура 11(71) • 2013}

«искусственных» произведений. Однако «искусность» произведенных Творцом произведений «естественна», а произведенных художником-творцом произведений неестественна, то есть «искусственно искусна», ибо непосредственно связана с человеческой «хитростью разума».

Произведение искусства, будучи элементом «второй» природы, обязано владеть «искусом», что означает функциональную способность подобной вещи к использованию её в качестве заразительно соблазняющего средства для достижения некой цели. При этом «искусно искусственный искус» произведения искусства родственен, но не тождественен «искусно естественному искусу» первоприродных произведений (художник стремится наполнить произведенные им произведения архитектуры, живописи, скульптуры формой и содержанием произведенных Творцом произведений, то есть жаждет творить так, как творит Природа).

Относительно небольшое пространство «искусственных искусно искушающих» вещей «второй» природы - это еще не сфера собственно произведений искусства. Подобное пространство позволительно расчленить на зону, где господствуют «подлинно конечные» второприродные вещи, и зону, где преобладают «иллюзорно конечные» произведения. В пространстве вещей «второй» природы, где доминирует функция, хозяйничает конечность. Но коли суть конечного не в конечном, а в его противоположности, то в пространстве второприродных вещей обязательно присутствуют предметы, ориентированные при стремлении к своей сути на прорыв конечности. Такими «иллюзорно конечными» вещами, мерно совмещающими в себе конечное и бесконечное, и являются произведения искусства.

Бытие всякой вещи предполагает, с одной стороны, пестование ею собственной индивидуальности, уникальности, самоцентрированности и самоутверждаемости. С другой стороны, бытие единичной вещи - это бытие в составе всеобщего целого, соучастие индивидуального в универсальном. Самоутверждение и соучастие как стороны бытия вещи различимы, но неразделимы. Быть частью неотъемлемый компонент быть неповторимым индивидом, а быть индивидом - неотъемлемый компонент быть частью. Самоутверждение бытия вещи есть в то же время соучастие в самоутверждении Полноты Бытия. Иное у людей. Разумно решившись на выход из мира первоприродных вещей и встав над ним, человек, кристаллизуясь в качестве человека, на протяжении жизни огранивает, ограничивает, оконечивает себя, что неотвратимо нарушает его ин- дивидуальное бытие как единство самоутверждения и соучастия. Чем интенсивнее процесс кристаллизации человека, тем меньше у него остается шансов для соучастия. Эгоцентрируя свою конечность через отношение со всем и вся конечным, человек и только человек превращает индивидуальную обособленность в отчуждение, самоцентрированность в себялюбие, самостоятельность - в честолюбие и желание власти над миром первоприродных вещей с помощью вещей второприродных.

Самоутверждение человека отвлекает его от соучастия в Полноте Бытия в сторону соучастия в строительстве его коллективистски индивидуализированного бытия как могущественного и самодостаточно космического центра. Если стремление вещи пребывать в своем бытии есть единство ее сущности и существования, то стремление человека обратить свое индивидуальное бытие в бытие универсальное есть не что иное, как разрыв сущности и существования. Расчленение же единства самоутверждения и соучастия на относительно самостоятельные элементы, отрицая индивидуальное бытие, ведет к распуханию небытия внутри бытия, к смерти при жизни. Развивая и укрепляя собственное самоутверждение, человек постепенно доводит ситуацию разрыва своего бытия как самоутверждения и бытия как соучастия до экстремальной, то есть до такого состояния, в котором бытие осознает возможность небытия, реактивно вызывая в особо острые периоды существования чувство тревоги, ужаса, отчаяния, тупика.

Однако, помня о собственном пренатальном соучастии единичного во всеобщем, человек, лишившийся при выходе из утробы матери плаценто-пуповины в качестве репрезентанта идеального отношения конечного с бесконечным, всю свою жизнь сознательно-бессознательно ищет более или менее корректную замену утраченному при рождении посреднику единства самоутверждения и соучастия ${ }^{1}$. Произведение искусства - это тот феномен, который в качестве «иллюзорно конечной» вещи способен выступить наиболее эффективным средством восстановления качества соучастия индивидуального бытия человека в самоутверждении универсального Бытия.

«Иллюзорно конечные» произведения искусства могут быть и являются «одномерными», «двухмерными» и «трехмерными», созданными в целях удовлетворения нужд соответственно «плотского»,

${ }^{1}$ Жуковский В.И. Теория изобразительного искусства: монография. СПб: Алетейя, 2011. С. 50-65. 


\section{Философия и искусство}

«душевного» и «духовного»аспектов человека. «Одномерные» и «двухмерные» произведения искусства преимущественно возникают в качестве репрезентантов идеального отношения конечного с конечным, ибо в их «иллюзорной конечности» мера единичного и конкретного относительно велика. «Трехмерные» произведения искусства обладают возможностью репрезентации идеального отношения конечного с бесконечным, потому что в их «иллюзорной конечности» доминирует общее и всеобщее.

Произведение искусства - это плод, для акта зачатия и процесса производства которого потребны как минимум два родителя. Таковыми для произведения изобразительного искусства выступают художник в роли своеобразного «отца» и художественныц̆ материал в роли своеобразной «матери» ${ }^{1}$.

Художник - это мастер-производитель, способный с помощью своего визуального мышления и технологических навыков умственного и практического действования преобразить художественный материал, наделенный «первичной» чувственностью, в нечто «вторично» чувственное.

Художественныц материал - это такое наличное бытие, которое, природно-синкретически объединяя в себе «единичное» и «общее», способно на структурированное преображение себя в феноменально-образцовое «особенное», где мера сущностно «общего», достигая всеобщей величины, максимально проявляется через уникальную конкретику «единичного».

Художник - владелец «субъект-языка». Он «искусный» или «суперискусный» либо «метаискусный» интегратор индивидуальных, социальных и общечеловеческих обязанностей:

во-первых, художник по долгу своей пренатальной памяти личностно заинтересован в производстве произведений искусства;

во-вторых, художник - тот, кто в составе определенного социального организма готов к выполнению функции органа, в нуждах общества производящего произведения;

в-третьих, художник - это некто, наделенный миссионерским даром свыше в угоду человечеству в целом и Абсолюту производить произведения искусства, способные оконечивать бесконечное и обесконечивать конечное.

\footnotetext{
${ }^{1}$ Жуковский В.И. Творческий процесс: художник и художественный материал в их искусности, искусственности и искусе // Философия и культура. 2013. № 4. С. 510-515.
}

Художественный материал - корректный представитель Абсолюта, носитель «объект-языка», обладатель потенциальной системы знаков, составляющих Книгу Природы.

Производство произведения изобразительного искусства происходит на площадке игрового отношения художника с художественным материалом, причем в качестве области взаимодействия «матери» и «отца» при сотворении плода-произведения выступает лоно художественного материала. Именно с плотью материала в процессе игрового отношения производятся изменения, в осуществлении которых принимают участие как художник-«отец», так и художественный материал-«мать». «Масочность» игры превращает субъект-объектное отношение оппонентов в отношение субъект-субъектное (анимизм присущ процессу производства всякого произведения искусства). Будучи при начале отношения личинами «ничто», художник и художественный материал как игровые партнеры в процессе взаимодействия проявляются друг через друга в качестве своеобразных «нечто», что в итоге приводит к кристаллизации произведенного произведения, предстающего как чувственно явленная сущность имеющей определенность бесконечности или единство конечного («нечто») и бесконечного («ничто»).

Многочисленные и разнообразные операционные действия «субъект-языка» художника и «объект-языка» художественного материала навстречу друг другу в пространстве их речевого отношения игрового характера приводят к порождению кооперативного эффекта нового качества, снимающего в своей целостности свойства соотносящихся сторон $^{2}$. Производится текст, сплетающий произведение искусства из нитей речевых высказываний «субъект-языка» и «объект-языка» в качестве Книги Откровения - художественно художническое толкование Книги Природы.

Произведенное «матерью»и «отцом» произведение искусства в своей доступности органам чувств человека - это, прежде всего «вещь-в-себе», достоверный габаритный объект, представленный системой предметных слоев, главным из которых выступает (в случае живописной картины) красочный системообразующий слой «форм» и «фона», сконструированных из «элементарных ячеек».

\footnotetext{
2 Жуковский В.И. Операционный подход к проблеме формирования художественного образа // Международный журнал прикладных и фундаментальных исследований. 2013. № 6. С. 44-46.
} 


\section{Философия и культура 11(71) • 2013}

Своеобразие произведения-вещи в том, что оно, оправдывая свое существование в качестве художественного творения, не есть лишь «вещь-в-себе», а есть единство вещественности и вещания. Это значит, что «вторичная» чувственность произведения искусства (прежде всего «трехмерного») произведена так, что всегда готова к игровому взаимодействию со зрителем на площадке своей вещественности, причем на персональное и сугубо интимное отношение с любым человеком человечества, независимо от его национальной, религиозной, возрастной, половой и пр. принадлежности во всякое мгновение своего исторического существования.

Каждое произведение искусства как «вещь-всебе» и традиционно, и инновационно.

С одной стороны, все живописные картины, созданные в разные времена и различными художниками, имеют красочный слой в качестве главного, что не может не роднить разнообразные произведениявещи друг с другом, указывая на традиционность их производства.

С другой стороны, каждая из миллионов картин располагает уникальной конструкцией «элементарных ячеек», «форм» и «фона» своей живописной поверхности, что делает каждое произведение-вещь принципиально отличным от всех других.

Произведение-вещь - это потенциальное художественное творение. Актуальным созданием изобразительного искусства является «произведение-в-открытости».

Родителями произведения изобразительного искусства в качестве «вещи-в-открытости» выступают двое: произведение-вещь в роли «матери» и зритель в роли «отца».

Зритель - это человек, вступивший в границы площадки игрового отношения с произведением искусства в его вещном и вещем состояниях. Человек не изначально зритель. Он должен еще достичь зрительского положения, получив соответствующие знания в области художественной культуры и доказав свою способность быть зрителем, то есть проявив талант искать и находить репрезентанты идеального отношения конечного с бесконечным в пространстве изобразительного искусства ${ }^{1}$.

Эталонный зритель в процессе «полагания» себя в произведение и «полагания» произведения в себя с необходимостью изменяется, становясь в зависи-

\footnotetext{
${ }^{1}$ Жуковский В.И. Характер и особенности диалога зрителя с произведением // Педагогика искусства: электрон. науч. журнал. 2010. № 2. (URL: http://www.art-education.ru /AEmagazine/new-magazine-2-2010.htm).
}

мости от меры кристаллизации художественного образа то зрителем-наблюдателем, то зрителемсобеседником, то зрителем-со-твориом.

Взаимодействие произведения изобразительного искусства со зрителем есть их операционное общение, совершаемое в форме речевых высказываний на «субъект-языке зрителя» и «объект-языке произведения» ${ }^{2}$.

Игровое отношение человека-зрителя с произведением-вещью, их соитие друг с другом, приводит к зачину, развитию и кристаллизации наглядного плода, имя которому «вещь-в-открытости» или «художественный образ» ${ }^{3}$. Именно художественный образ как плод отношения-диалога зрителя и произведения-вещи есть произведение изобразительного искусства, тогда как продукт, произведенный совместными усилиями художника и художественного материала - это еще некий «полуфабрикат», для своего преображения в произведение изобразительного искусства требующий соответствующего взаимодействия с достойным зрителем.

Многочисленность произведений изобразительного искусства и их градация на рядовые работы и шедевры связана с тем, что художественный образ как модель Бытия при всем стремлении к эталонности не в состоянии стать полной моделью, ибо всякий подобный «квазиобъект» заведомо «грешен» однобокостью и примитивизацией. Полнота Бытия не может быть в принципе выражена посредством какого-либо единичного и конкретного произведения искусства, а, следовательно, и индивидуального художественного образа (как не может многогранник при даже бесконечном увеличении его сторон потерять собственное гранение и стать окружностью). Однако стремление достичь невозможных вершин совершенства стимулирует художников совместно с художественным материалом изо дня в день, из года в год, из века в век производить «иллюзорно-конечные» произведения-вещи, которые вместе с совершенными зрителями в конце концов построят художественные образы, способные объединить в целое конечное несовершенство с бесконечным Совершенством.

\footnotetext{
2 Жуковский В.И. Операционный подход к проблеме формирования художественного образа // Международный журнал прикладных и фундаментальных исследований. 2013. № 6. C. 44-46.

3 Жуковский В.И. Структурные основы теории изобразительного искусства // Философия и культура. 2012. № 3. С. 96-104.
} 


\section{Философия и искусство}

\section{Список литературь:}

1. Власов В. Г. Большой энциклопедический словарь изобразительного искусства:

В 8-и т. СПб: ЛИТА, 2000. Т. 3. 847 с.

2. Даль В. И. Толковый словарь живого великорусского языка: В 4-х т. М., 1980. Т. 4. 683 с.

3. Ж Жуковсий В.И. О проблеме самодвижения в изобразительном искусстве // Международный журнал экспериментального образования. 2013. № 7. С. 138-139.

4. Жуковский В.И. Операционный подход к проблеме формирования художественного образа // Международный журнал прикладных и фундаментальных исследований. 2013. № 6. С. 44-46.

5. Жуковский В. И. Произведение искусства: особенности производства и специфика потребления // Международный журнал прикладных и фундаментальных исследований. 2013. № 4. С. 76-79.

6. Жуковский В.И. Структурные основы теории изобразительного искусства // Философия и культура. 2012. № 3. С. 96-104.

7. Жуковский В. И. Творческий процесс: художник и художественный материал в их искусности, искусственности и искусе // Философия и культура. 2013. № 4. С. 510-515.

8. Жуковский В.И. Теория изобразительного искусства: монография. СПб: Алетейя, 2011.496 с.: ил.

9. Жуковский В.И Характер и особенности диалога зрителя с произведением //

Педагогика искусства: электрон. науч. журнал. 2010. № 2.

(http://www.art-education.ru/AE-magazine/new-magazine-2-2010.htm).

10. Жуковский В.И., Пивоваров Д. В. Природа визуального мышления // Журнал Сибирского федерального университета. Гуманитарные науки. 2008. № 1 (1). С. $149-158$.

11. Жуковский В.И., Тарасова М.В. Идеалофундированная система культуры: принцип строения, диалектика самодвижения и саморазвития // Философия и культура. 2011. № 6. С. 65-72.

12. Жуковский В.И., Тарасова М. В. Культура как идеалофундированная система // Вопросы культурологии. 2013. № 1 .

13. Пивоваров Д. В. Проблема синтеза основных дефиниций культуры // Вестник Российского философского общества. 2009. № 1. С. 157-161.

14. Пивоваров Д. В. Философия религии. М: Академический проект; Екатеринбург: Деловая книга, 2006. 640 с.

15. Современный словарь-справочник по искусству / Науч. ред. и сост. А. А. Мелик-Пашаев. М.: Олимп: АСТ, 1999. 813 с.

16. Фасмер М. Этимологический словарь русского языка: В 4-х т. М.: Прогресс, 1986. Т. 2. 672 с.

17. Zhukovskiy V.I., Pivovarov D. W. About a problem of is religious-art expression of an ideal of «the perfect person» in Russian art culture // Journal of Siberian Federal University.

Humanities \& Social Sciences. 2012. № 1 (1). C. 48-55.

18. Zhukovskiy V.I., Pivovarov V.D. Characteristics of visual thinking The // European journal of natural history. 2009. № 6. P. 38-44.

19. Zhukovskiy V.I., Pivovarov D. W. The Nature of Visual Thinking // Journal of Siberian Federal University. Humanities \& Social Sciences. 2008. № 1 (1). P. 124-148.

20. Zhukovskiy V.I., Pivovarov D. W. Works of art and visual thinking // European journal of natural history. 2010. № 2. P. 38-42.

21. Pivovarov D. V. Ideale and Ideelle // Journal of Siberian Federal University: Humanities \& Social Sciences. 2012. № 5 (1). C. 13-27.

22. Pivovarov D. V. Problem of Synthesis of the Main Definitions of Culture // Journal of Siberian Federal University: Humanities \& Social Sciences. 2009. T. 2. № 1. C. 17-22.

\section{References (transliteration):}

1. Vlasov V. G. Bol'shoi entsiklopedicheskii slovar» izobrazitel'nogo iskusstva: V 8-i t. SPb: LITA, 2000. T. 3.847 c.

2. Dal» V.I. Tolkovyi slovar» zhivogo velikorusskogo yazyka: V 4-h t. M., 1980. T. 4. 683 s.

3. Zhukovskii V.I. O probleme samodvizheniya v izobrazitel'nom iskusstve // Mezhdunarodnyi zhurnal eksperimental’nogo obrazovaniya. 2013. № 7. S. 138-139. 


\section{Философия и культура 11(71) • 2013}

4. Zhukovskii V.I. Operatsionnyi podkhod k probleme formirovaniya khudozhestvennogo obraza // Mezhdunarodnyi zhurnal prikladnykh i fundamental'nykh issledovanii. 2013. № 6. S. 44-46.

5. Zhukovskii V. I. Proizvedenie iskusstva: osobennosti proizvodstva i spetsifika potrebleniya // Mezhdunarodnyi zhurnal prikladnykh i fundamental'nykh issledovanii. 2013. № 4. C. 76-79.

6. Zhukovskii V.I. Strukturnye osnovy teorii izobrazitel'nogo iskusstva // Filosofiya i kul'tura. 2012. № 3. S. 96-104.

7. Zhukovskii V.I. Tvorcheskii protsess: khudozhnik i khudozhestvennyi material v ikh iskusnosti, iskusstvennosti i iskuse // Filosofiya i kul'tura. 2013. № 4. S. 510-515.

8. Zhukovskii V.I. Teoriya izobrazitel'nogo iskusstva: monografiya. SPb: Aleteiya, 2011. 496 s.: il.

9. Zhukovskii V.I Kharakter i osobennosti dialoga zritelya s proizvedeniem // Pedagogika iskusstva: elektron. nauch. zhurnal. 2010. № 2. (http://www.art-education.ru /AE-magazine/new-magazine-2-2010.htm).

10. Zhukovskii V.I., Pivovarov D. V. Priroda vizual'nogo myshleniya // Zhurnal Sibirskogo federal'nogo universiteta. Gumanitarnye nauki. 2008. № 1 (1). S. 149-158.

11. Zhukovskii V.I., Tarasova M. V. Idealofundirovannaya sistema kul'tury: printsip stroeniya, dialektika samodvizheniya i samorazvitiya // Filosofiya i kul'tura. 2011. № 6. S. 65-72.

12. Zhukovskii V.I., Tarasova M. V. Kul'tura kak idealofundirovannaya sistema // Voprosy kul'turologii. 2013. № 1.

13. Pivovarov D. V. Problema sinteza osnovnykh definitsii kul'tury // Vestnik Rossiiskogo filosofskogo obshchestva. 2009. № 1. S. 157-161.

14. Pivovarov D. V. Filosofiya religii. M: Akademicheskii proekt; Ekaterinburg: Delovaya kniga, 2006. $640 \mathrm{~s}$.

15. Sovremennyi slovar'-spravochnik po iskusstvu / Nauch. red. i sost. A. A. Melik-Pashaev. M.: Olimp: AST, 1999. 813 s.

16. Fasmer M. Etimologicheskii slovar» russkogo yazyka: V 4-h t. M.: Progress, 1986. T. 2. 672 s. 